\title{
Evidence for Cortical Inhibitory and Excitatory Dysfunction in Obsessive Compulsive Disorder
}

\author{
Margaret A Richter 1,6, Danilo R de Jesus ${ }^{2,6}$, Sylco Hoppenbrouwers ${ }^{3}$, Melissa Daigle ${ }^{2}$, Jasna Deluce ${ }^{4}$, \\ Lakshmi N Ravindran ${ }^{2}$, Paul B Fitzgerald ${ }^{5}$ and Zafiris J Daskalakis*,2 \\ 'Director of OCD and Related Disorders, Department of Psychiatry, Sunnybrook Health Sciences Centre, Toronto, Ontario, Canada; ${ }^{2}$ Centre \\ for Addiction and Mental Health, University of Toronto, Toronto, Ontario, Canada; ${ }^{3}$ Department of Psychology, Utrecht University, Utrecht, \\ The Netherlands; ${ }^{4}$ Department of Psychiatry, Sunnybrook Health Sciences Centre, Toronto, Ontario, Canada; ${ }^{5}$ Monash Alfred Psychiatry Research \\ Centre, The Alfred and Monash University School of Psychology and Psychiatry, Melbourne, Victoria, Australia
}

Several lines of evidence suggest that obsessive-compulsive disorder (OCD) is associated with an inability to inhibit unwanted intrusive thoughts. The neurophysiological mechanisms mediating such inhibitory deficits include abnormalities in cortical $\gamma$-aminobutyric acid (GABA) inhibitory as well as N-methyl-D-aspartate (NMDA) receptor-mediated mechanisms. Molecular evidence suggests that both these neurotransmitter systems are involved in OCD. Transcranial magnetic stimulation (TMS) represents a noninvasive technique to ascertain neurophysiological indices of inhibitory GABA and facilitatory NMDA receptor-mediated mechanisms. In this study, both mechanisms were indexed in 34 patients with OCD (23 unmedicated and II medicated) and compared with 34 healthy subjects. Cortical inhibitory and facilitatory neurotransmission was measured using TMS paradigms known as short-interval cortical inhibition $(\mathrm{SICl})$, cortical silent period (CSP), and intracortical facilitation (ICF). Patients with OCD demonstrated significantly shortened CSP $(p<0.00 \mathrm{I}$, Cohen's $d=0.9 \mathrm{I})$ and increased ICF $(p<0.009$, Cohen's $d=0.7 \mathrm{I})$ compared with healthy subjects. By contrast, there were no significant deficits in $\mathrm{SICl}$. After excluding patients with $\mathrm{OCD}$ and comorbid major depressive disorder (MDD) from the analysis, these differences remained significant. Our findings suggest that $O C D$ is associated with dysregulation in cortical inhibitory and facilitatory neurotransmission. Specifically, these findings suggest impairments in GABA $B$ receptor-mediated and NMDA receptor-mediated neurotransmission. These findings are consistent with previously published genetic studies implicating GABA $A_{B}$, and NMDA transporter and receptor genes in OCD. It is posited that dysregulation of such mechanisms may lead to the generation and persistence of intrusive thoughts that form the basis for this disorder.

Neuropsychopharmacology (2012) 37, I|44-1 I5 I; doi: I0.1038/npp.20 I I.300; published online I4 December 20 I I

Keywords: GABA; OCD; TMS; physiology; inhibition; cortical

\section{INTRODUCTION}

Obsessive-compulsive disorder (OCD) has a lifetime prevalence of 2-3\% (Karno et al, 1988; Ruscio et al, 2010; Weissman et al, 1994) and is associated with high psychosocial morbidity (Koran et al, 1996; Richter et al, 2003). Neuroimaging studies have implicated dysfunction in frontostriatal circuitry in the pathophysiology of OCD (Graybiel and Rauch 2000; Saxena et al, 1998; Whiteside et al, 2004), demonstrating abnormal metabolic activity in

\footnotetext{
*Correspondence: Dr ZJ Daskalakis, Staff Psychiatrist, Schizophrenia Program, Associate Professor of Psychiatry, Centre for Addiction and Mental Health, Faculty of Medicine, University of Toronto, Toronto, Ontario M5TIR8, Canada, Tel: + I 416535850I × 4319, Fax: + I 4l6979 6936, E-mail: Jeff_Daskalakis@camh.net

${ }^{6}$ Drs Richter and de Jesus contributed equally and should be considered co-first authors for publication purposes.

Received 18 May 2011; revised 23 October 2011; accepted 29 October 2011
}

the orbitofrontal cortex, anterior cingulate cortex (ACC), medial prefrontal cortex, and caudate nucleus. Functional magnetic resonance imaging (fMRI) studies have provided further evidence for inhibitory dysregulation in OCD by demonstrating increased activation in the bilateral-ventrolateral prefrontal cortex, ACC, parahippocampal cortices, left temporal cortex, and in the dorsal brainstem (van den Heuvel et al, 2005). Neurophysiological studies also demonstrate enhanced precentral somatosensory evoked potentials, and a tonic high level of cortical excitability of motor and related areas (Rossi et al, 2005). Investigations of neurocognitive function in tandem with fMRI have suggested that this may relate to deficits in cognitive inhibitory function and response control (Chamberlain et al, 2005; Page et al, 2009; Woolley et al, 2008). For example, OCD patients tend to make inappropriate motor responses to non-target stimuli when performing Go/No-Go tasks, in which subjects have to make a simple motor response (such as pressing a button) as quickly as possible 
when target/non-target stimuli are presented (Maltby et al, 2005; Page et al, 2009). Such alterations may lead to a reduced ability of patients to inhibit intrusive thoughts, impulses, images, and repetitive motor responses (Yucel et al, 2007), creating the clinical phenomena of OCD.

Additional evidence supports the involvement of $\gamma$-aminobutyric acid (GABA) and glutamatergic neurotransmission in OCD, including magnetic resonance spectroscopy studies, which suggest alterations in glutamate concentrations in the caudate in pediatric OCD (Rosenberg et al, 2000), and genetic studies implicating the glutamate transporter gene SLC1A1 (Arnold et al, 2006; Dickel et al, 2006), the glutamate N-Methyl-D-aspartate (NMDA) subunit receptor gene GRIN2B (Arnold et al, 2004; Dickel et al, 2006), as well as the $\mathrm{GABA}_{\mathrm{B}}$ receptor 1 (GABBR1) gene as susceptibility genes in OCD (Zai et al, 2005). Collectively the above represents compelling evidence that OCD is associated with deficient inhibition and excessive facilitation in the cortex.

Transcranial magnetic stimulation (TMS) represents a noninvasive method through which to assess brain inhibitory neurotransmission. Two of the main inhibitory paradigms used are short-interval cortical inhibition (SICI) and cortical silent period (CSP) (Cantello et al, 1992; Kujirai et al, 1993). SICI consists of a subthreshold conditioning pulse followed by a suprathreshold test pulse. If the interstimulus interval (ISI) ranges from 1 to $5 \mathrm{~ms}$, the motor-evoked potential (MEP) response is inhibited by 50-90\% (Kujirai et al, 1993). In CSP, motor cortical stimulation is superimposed on background electromyographic activity. A cessation of electromyographic activity occurs, producing a silent period (Fuhr et al, 1991). SICI and CSP appear to reflect cortical GABAergic inhibitory neurotransmission. SICI appears to index $\mathrm{GABA}_{\mathrm{A}}$ receptormediated inhibition (Ziemann et al, 1996a), whereas CSP is more closely related to $\mathrm{GABA}_{\mathrm{B}}$ receptor-mediated inhibition (Siebner et al, 1998; Werhahn et al, 1999). For example, it has been shown that lorazepam, a drug that facilitates $\mathrm{GABA}_{\mathrm{A}}$ neurotransmission, increases SICI (Ziemann et al, 1996b). Moreover, the duration of SICI is comparable to the duration of $\mathrm{GABA}_{\mathrm{A}}$-mediated inhibitory postsynaptic potentials (IPSPs) (Davies et al, 1990). Also, the CSP demonstrates a similar time course as the $\mathrm{GABA}_{\mathrm{B}}$ receptorinduced IPSP (Roick et al, 1993) and baclofen, a GABA agonist, leads to CSP lengthening (Siebner et al, 1998). TMS can also be used to examine cortical facilitation using the paired pulse paradigm known as intracortical facilitation (ICF), in which a subthreshold conditioning pulse precedes a suprathreshold test pulse by $10-20 \mathrm{~ms}$ and results in MEP potentiation compared with the suprathreshold test pulse alone. ICF reflects the activity of excitatory postsynaptic potentials transmitted by NMDA glutamate receptors (Ziemann et al, 1998).

Three studies have examined SICI, CSP, and ICF in OCD. Greenberg et al, 1998 compared 12 OCD patients (7 on fluoxetine and 5 unmedicated) with 12 healthy volunteers. They reported that OCD patients had decreased SICI (Greenberg et al, 1998). The same author conducted a second study in which 16 OCD patients were enrolled (9 medicated and 7 unmedicated). OCD patients had decreased SICI compared with 11 healthy controls. No differences in CSP were found (Greenberg et al, 2000).
Finally, a study comparing 20 subjects with Tourette's Disorder (TD) and comorbid OCD, and attention deficit hyperactivity disorder with 21 healthy controls showed that OCD patients had shortened CSP and decreased SICI (Ziemann et al, 1997a).

In this study, we aimed to investigate SICI, CSP, and ICF in a larger and primarily unmedicated sample of OCD patients. Based on the molecular findings described above, we hypothesized that OCD patients would demonstrate neurophysiological deficits that were consistent with dysregulation of $\mathrm{GABA}_{\mathrm{B}}$ and NMDA neurotransmission.

\section{PATIENTS AND METHODS}

\section{Subjects}

This study included 34 right-handed patients (mean age $=40.94 \pm 12.38$ years, 15 men and 19 women) with a DSM-IV diagnosis of OCD confirmed by the Structured Clinical Interview for DSM-IV (SCID), and 34 matched healthy right-handed volunteers (mean age $=40.41 \pm 10.26$ years, 16 men and 18 women). In healthy subjects, psychopathology was ruled out using the personality assessment inventory (PAI; Psychological Assessment Resources). The PAI is a self-administered, objective inventory of adult personality and psychopathology (eg, personality, depression, somatic disorders, anxiety, anxiety-related disorders, and schizophrenia). It is composed of nonoverlapping clinical, treatment, interpersonal, and validity scales. Specifically, the PAI measures manifestation of clinical syndromes, providing information to assist diagnosis, treatment, and screening for all psychopathology corresponding to DSM-IV categories (Morey, 1991, 1996). For healthy controls, exclusion criteria included a selfreported comorbid medical illness or a history of drug or alcohol abuse. Patients with OCD had a history of at least 1 year of duration of symptoms and were between 18 and 65 years of age. Exclusion criteria included comorbid schizophrenia, psychotic or bipolar affective disorder, neurological disease, as identified by history and/or laboratory screening, active drug or alcohol abuse, any comorbid medical condition that might require urgent intervention, and current pregnancy.

Among the 34 patients with OCD, 23 were unmedicated and 11 were medicated. Details regarding medication status are listed in Table 1. Individuals were deemed unmedicated if treatment with serotonin reuptake inhibitors had been discontinued at least 2 weeks before measures were collected (5 weeks washout minimum for fluoxetine) and were not taking any other CNS active medications (eg, benzodiazepines, antipsychotics, NMDA antagonists, mood stabilizers, and antiepileptic drugs). The severity of OCD was assessed using the Yale-Brown Obsessive Compulsive Scale (Y-BOCS), which includes 10 items for rating severity, and a symptom checklist itemizing 45 obsessions and 29 compulsions (Goodman et al, 1989a, b). The checklist items were used to derive weighted symptom factor scores for four factors calculated by totaling number of items loading on each factor endorsed by the patient and dividing by total number of possible items based on factor analysis of the Y-BOCS (Summerfeldt et al, 1999). The four factors comprised: Factor 1, aggressive obsessions, sexual 
Table I Demographic and Clinical Characteristics of the Sample

\begin{tabular}{|c|c|c|}
\hline & $\begin{array}{l}\text { OCD group } \\
(n=34)\end{array}$ & $\begin{array}{l}\text { Control group } \\
\quad(n=34)\end{array}$ \\
\hline $\mathrm{Age}^{\mathrm{a}}$ & $40.9 \pm 12.38$ & $40.41 \pm 10.26$ \\
\hline \multirow[t]{2}{*}{ Gender } & I5 Male & 16 Male \\
\hline & 19 Female & I8 Female \\
\hline Mean illness duration & $16.65 \pm 8.48$ & NA \\
\hline Y-BOCS scores current ${ }^{\mathrm{a}}$ & $24.34 \pm 6.32$ & NA \\
\hline Y-BOCS lifetime ${ }^{a}$ & $24.43 \pm 8.25$ & NA \\
\hline BDI scores current ${ }^{\mathrm{a}}$ & $22.75 \pm 13.85$ & NA \\
\hline $\begin{array}{l}\text { Medications (\# of subjects, } \\
\text { mean dose in } \mathrm{mg} \text { ) }\end{array}$ & $\begin{array}{l}\text { Sertraline }(1,100) \\
\text { Citalopram }(2,140) \\
\text { Quetiapine }(3,217) \\
\text { Venlafaxine }(5,390) \\
\text { Trazodone }(1,100) \\
\text { Gabapentine }(2,2100) \\
\text { Topiramate }(1,50) \\
\text { Methylphenidate }(1,80) \\
\text { Paroxetine }(4,70) \\
\text { Lorazepam }(2,1) \\
\text { Fluvoxamine }(1,160) \\
\text { Fluoxetine }(1,20) \\
\text { Tryptophan }(1,4000) \\
\text { Pimozide }(1,3)\end{array}$ & NA \\
\hline
\end{tabular}

Abbreviations: $\mathrm{BDI}$, beck depression inventory; $\mathrm{OCD}$, obsessive compulsive disorder; Y-BOCS, Yale-Brown Obsessive Compulsive Scale.

${ }^{a}$ Data reported as mean \pm SD

obsessions, religious obsessions, somatic obsessions, and checking compulsions; Factor 2, obsessions with need for symmetry or exactness, repeating rituals, counting compulsions, and ordering/arranging compulsions; Factor 3, contamination obsessions and cleaning/washing compulsions; Factor 4, hoarding/saving obsessions and hoarding/ collecting compulsions. Depressive symptoms were rated with the Beck Depression Inventory (BDI). Utilizing a BDI cutoff score of 21 (Beck and Beamesderfer 1974), 26.7\% of patients with OCD had comorbid depressive symptoms of moderate severity or greater. Based on SCID interview, none of the patients met criteria for Tourette's syndrome. With regard to other comorbid disorders, one (3\%) patient with OCD had comorbid agoraphobia, three $(9 \%)$ had panic disorder, one (3\%) had trichotillomania, two (6\%) had social phobia, two (6\%) had generalized anxiety disorder, one (3\%) had skin picking, and three (9\%) had specific phobia. Demographic and clinical data for the two groups (ie, patients with OCD and healthy subjects) are listed in Table 1. All subjects reported no drug or alcohol use in the month before testing on SCID interview. This study was approved by the Centre for Addiction and Mental Health Ethics committee, and written informed consent was obtained for each participant.

\section{Procedures}

TMS was applied to the hand area of the left motor cortex with a figure-of-eight magnetic coil and two Magstim 200 magnetic stimulators (Magstim, Whitland, Dyfed, UK). The coil diameter was $70 \mathrm{~mm}$ for each loop. The coil was held tangentially on the head with the handle pointing backward and $45^{\circ}$ laterally from the midline. Surface electromyography (EMG) was recorded from the right abductor pollicis brevis (APB) muscle. Subjects were comfortably seated in a chair and maintained a relaxed state throughout the experiment. The RMT was defined as the minimal intensity that produced a MEP of $>50 \mu \mathrm{V}$ in 5 of 10 trials in relaxed APB (Kujirai et al, 1993). Measurement of the CSP duration was obtained in moderately tonically active APB (ie, $20 \%$ of maximum contraction) by stimulating the motor cortex with intensities of $140 \%$ of RMT. This intensity was chosen based on the evidence that suggests that CSP duration at lower stimulus intensities (110 and $120 \%$ of MT) mainly reflects activation of $\mathrm{GABA}_{\mathrm{A}}$ receptors, whereas CSP duration at the higher stimulus intensities $\left(140 \%\right.$ of MT) mainly reflects the activation of $\mathrm{GABA}_{\mathrm{B}}$ receptors (Paulus et al, 2008). A total of 10 trials were performed. The CSP duration was the time from the MEP onset to the return of any voluntary EMG activity. This is referred to as the absolute CSP and ends with a deflection in the EMG waveform (Tergau et al, 1999). The CSP was determined with our previously published automated method (Daskalakis et al, 2003). In SICI, a subthreshold conditioning stimulus, which was set at $80 \%$ of RMT, preceded a suprathreshold test stimulus (TS), which was adjusted to produce an average MEP of $0.5-1.5-\mathrm{mV}$ peak-to-peak amplitude in the contralateral APB muscle (Kujirai et al, 1993). Conditioning stimuli were applied to the motor cortex before the TS at one of five random ISIs: 2 and $4 \mathrm{~ms}$ for SICI and 10, 15, and $20 \mathrm{~ms}$ for ICF. A total of 72 trials were performed, 12 for each condition. For SICI/ICF, changes in the TS MEP amplitude at each ISI were expressed as a percentage of the mean unconditioned MEP amplitude (Daskalakis et al, $2002 \mathrm{~b}$ ). The order of administration of the two paradigms was counterbalanced between subjects to prevent order effects.

\section{Statistical Analysis}

Demographic characteristics and severity of clinical symptoms were compared among OCD patients by $\chi^{2}$ test (for categorical variables). Both the OCD patients and healthy controls groups were checked for outliers. Independent samples $t$-tests were used to test for differences in RMT, CSP, and SICI/ICF between healthy controls and OCD patients, and also for differences in RMT and CI measures between medicated and unmedicated patients. Pearson's correlation coefficient was used for exploring associations between TMS indices (ie, SICI/ICF and CSP) and Y-BOCS total scores, weighted scores for factors $1-4$, obsessions and compulsions severity subscales of the Y-BOCS, and BDI scores. In the CSP experiment, the CSP duration served as the dependant variable. For SICI/ICF, the conditioned MEP size, expressed as a ratio of the MEP amplitude of each conditioned response to the unconditioned response at each ISI, served as the dependant variable. All statistical procedures were two-tailed, and significance was set at a $\alpha$ level of 0.05 . All analyses were computed with SPSS 15.0 (Statistical Product and Service Solutions, Chicago, IL). 


\section{RESULTS}

All subjects tolerated the study without difficulty. There was no significant difference between groups in the percentage of male subjects $\left(\chi^{2}=0.362, p=0.547\right)$ or in age (OCD patients, mean $\pm S D, 40.9 \pm 12.38$; healthy controls, $40.41 \pm 10.26, p=0.848)$. There were no significant differences in Y-BOCS scores between medicated and unmedicated patients with $\operatorname{OCD}(t(27)=-0.789, p=0.437)$. Also, there was no significant difference between medicated and unmedicated patients with $O C D$ in the number of years since the diagnosis of OCD $(p=0.348)$.

\section{Cortical Silent Period}

Patients with OCD had significant shorter CSP (mean \pm $\mathrm{SD}=122 \pm 36.3 \mathrm{~ms}$ ) compared with healthy controls $(153.5 \pm 32 \mathrm{~ms})(t(66)=-3.8, p<0.0001$, Cohen's $d=0.91)$ (Figure 1). There was no significant difference in CSP durations between medicated and unmedicated OCD patients $(t(32)=-0.261, p=0.796)$ (Figure 2). After excluding OCD patients with comorbid MDD (OCD/MDD) from the analysis, the difference in CSP between OCD

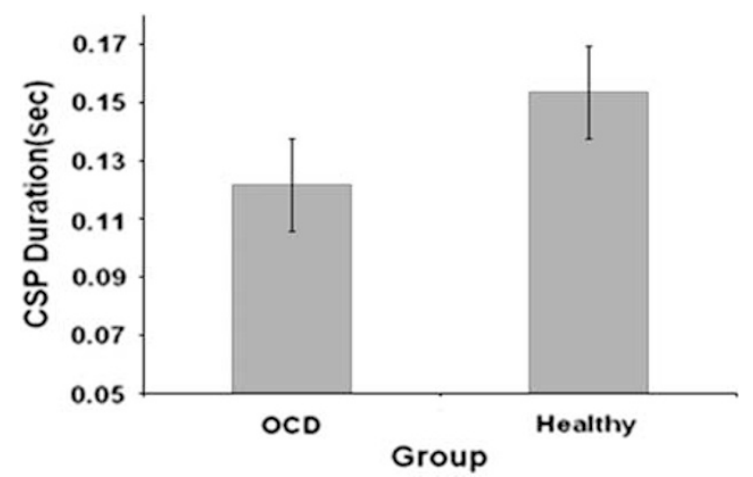

Figure I Mean cortical silent period (CSP) duration in 34 patients with obsessive compulsive disorder (OCD) and 34 healthy subjects. Values represent means \pm SEMs. There were significant CSP deficits in patients with OCD compared with healthy subjects $(t(66)=-3.8, p<0.000$ I, Cohen's $d=0.91$ ).

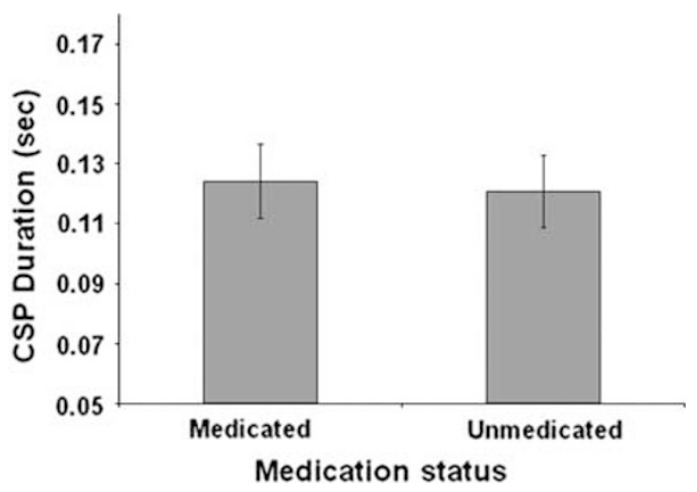

Figure 2 Mean cortical silent period (CSP) duration in medicated and unmedicated patients with OCD. Values represent means \pm SEMs. There was no statistically significant difference in CSP duration between medicated and unmedicated patients with $\mathrm{OCD}(t(32)=-0.26 \mathrm{I}$, $p=0.796)$. Other abbreviations as in Figure I. patients and healthy controls remained significant $(p=0.032)$. Also, there was a difference in CSP between OCD/MDD patients and healthy controls $(p=0.028)$. There were no significant correlations between CSP and Y-BOCS scores $(r=-0.026, p=0.894)$ or BDI scores $(r=-0.071$, $p=0.810)$ in OCD patients. Analyzing medicated and unmedicated OCD patients as two separate groups, no correlations were found between Y-BOCS scores and CSP in medicated patients $(r=0.153, p=0.743)$ or in unmedicated OCD patients $(r=-0.11, p=0.63)$. Also, no correlations were found between CSP and Factor $1 \quad(r=-0.068$, $p=0.71), \quad$ Factor $2 \quad(r=-0.11, \quad p=0.54)$, Factor 3 $(r=-0.10, p=0.59)$, and Factor $4(r=-0.88, p=0.637)$ of the Y-BOCS. Finally, no correlations were found between CSP, and obsessions and compulsions severity subscales of the Y-BOCS (all $p$ values $>0.210$ ).

\section{Short-Interval Cortical Inhibition}

There was no difference in unconditioned TS MEP amplitude between controls (mean $\pm \mathrm{SD}=0.895 \pm 0.267 \mathrm{mV}$ ) and $\mathrm{OCD}$ patients $(0.980 \pm 0.329 \mathrm{mV}) \quad(p=0.274)$. There were no significant differences in mean SICI between OCD patients (mean $\pm \mathrm{SD}=0.736 \pm 0.55$ ) and controls (mean \pm $\mathrm{SD}=0.565 \pm 0.34) \quad(t(63)=1.5, p=0.137)$. There was no significant difference in mean SICI between medicated and unmedicated patients with OCD $(t(29)=-0.108, p=0.915)$. When we compared OCD/MDD patients to healthy controls, the former had significantly decreased SICI compared with the latter $(p<0.001)$. Also, OCD/MDD patients had decreased SICI compared with OCD patients without MDD $(p<0.001)$. By contrast, there was no difference in SICI between OCD patients without comorbid MDD and healthy controls $(p=0.99)$. There were no significant correlations between SICI and Y-BOCS scores $(r=-1.22, p=0.553)$ or BDI scores $(r=0.446, p=0.169)$ in OCD patients. Analyzing medicated and unmedicated OCD patients as two separate groups, no correlations were found between Y-BOCS scores and SICI in medicated patients $(r=-0.442, p=0.38)$ or in unmedicated OCD patients $(r=0.005, p=0.985)$. Also, no correlations were found between SICI and Factors 1, 2, 3, and 4 of the Y-BOCS (all $p$ values $>0.146$ ). Finally, no correlations were

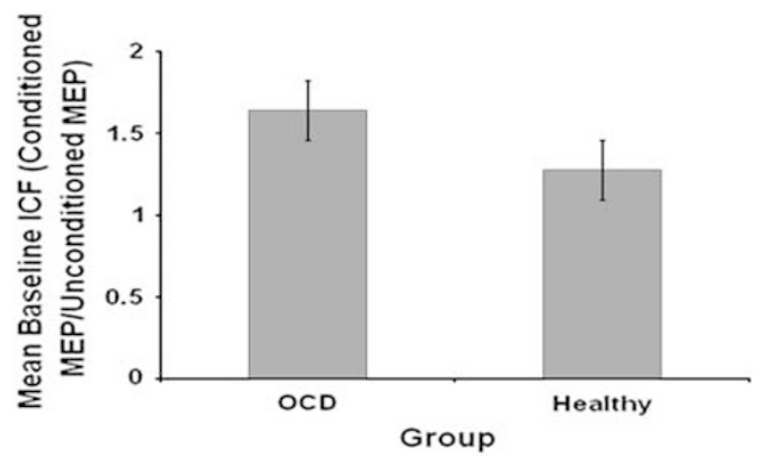

Figure 3 Mean intra-cortical facilitation (ICF) in patients with OCD and healthy subjects. Each measure is expressed as a ratio (mean \pm SEM) of the conditioned motor evoked potential (MEP) amplitude to the unconditioned MEP amplitude. ICF was significantly greater in OCD patients than in healthy controls $(t(60)=2.7, p=0.009$, Cohen's $d=0.7 \mathrm{I})$. Other abbreviations as in Figures $I$ and 2. 


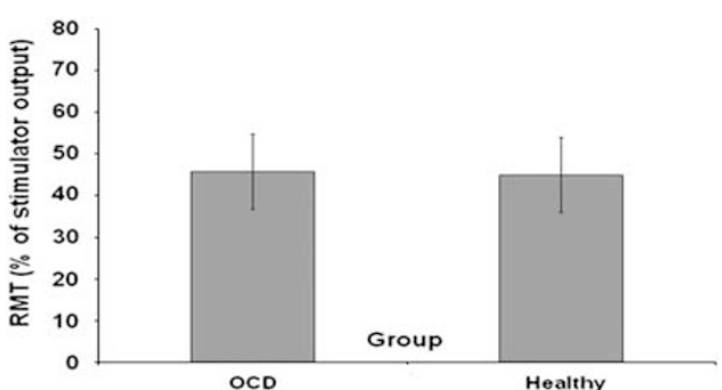

Figure 4 Resting motor threshold (RMT) in OCD patients and healthy subjects. The RMT was defined as the first intensity that produced an MEP of $>50 \mu \mathrm{V}$ in 5 of 10 trials with the abductor pollicis brevis muscle relaxed. Values represent means \pm SEMs. The RMT over the left motor cortex was not significantly different in OCD patients compared with healthy subjects $(t(62)=0.339, p=0.735)$. Other abbreviations as in Figures I, 2 and 3 .

found between SICI, and obsessions and compulsions severity subscales of the Y-BOCS (all $p$ values $>0.865$ ).

\section{Intracortical Facilitation}

The amplitude of the unconditioned TS was the same as for SICI and did not differ between groups $(p=0.274)$. ICF was significantly greater in OCD patients $(1.606 \pm 0.663)$ than in healthy controls $(1.276 \pm 0.418) \quad(t(60)=2.7$, $p=0.009$, Cohen's $d=0.71$ ) (Figure 3 ). There was no significant difference in mean ICF between medicated and unmedicated OCD patients $(t(29)=-0.397$, $p=0.694)$. After excluding OCD/MDD patients from the analysis, the difference in ICF between OCD patients and healthy controls remained significant $(p=0.045)$. There were no significant correlations between ICF and Y-BOCS scores $(r=-0.032, p=0.877)$ or BDI scores $(r=0.082$, $p=0.810)$ in OCD patients. No significant correlations were found between Y-BOCS total scores and ICF in medicated patients $(r=-0.053, p=0.92)$ or in unmedicated OCD patients $(r=-0.032, p=0.894)$. Also, no correlations were found between ICF and Factors 1, 2, 3, and 4 of the Y-BOCS (all $p$ values $>0.146$ ). Finally, no correlations were found between ICF, and obsessions and compulsions severity subscales of the Y-BOCS (all $p$ values $>0.424$ ).

\section{Motor Threshold}

The RMT over the left motor cortex was not significantly different in OCD patients (mean $\pm \mathrm{SD}=45.63 \pm 9.83)$ compared with healthy subjects $(44.85 \pm 8.56)(t(62)=0.339$, $p=0.735$ ) (Figure 4). There was a significant difference in RMT between medicated $(40.2 \pm 6.5)$ and unmedicated OCD patients $(48.35 \pm 10.2)(t(29)=2.29, p=0.03)$. The RMT over the left motor cortex was significantly higher in OCD/MDD patients (mean $\pm \mathrm{SD}=54 \pm 14.28$ ) compared with healthy controls (mean $\pm \mathrm{SD}=44.8 \pm 8.5) \quad(p=0.014)$ and with patients with OCD without MDD (mean \pm $\mathrm{SD}=43.21 \pm 4.8) \quad(p=0.010)$. In contrast, there was no significant difference in RMT between OCD patients without comorbid MDD and healthy controls $(p=0.557)$. There were no significant correlations between RMT and Y-BOCS scores $(r=-0.064, p=0.762)$ or BDI scores $(r=0.082$, $p=0.21)$ in OCD patients. Analyzing medicated and unmedicated patients with OCD as two separate groups, no correlations were found between Y-BOCS scores and RMT in medicated patients $(r=0.442, p=0.38)$ or in unmedicated OCD patients $(r=-0.07, p=0.776)$. Also, no correlations were found between RMT and Factors 1, 2, 3, and 4 of the Y-BOCS (all $p$ values $>0.202$ ). Finally, no correlations were found between RMT, and obsessions and compulsions severity subscales of the Y-BOCS (all $p$ values $>0.864$ ).

\section{DISCUSSION}

Our findings suggest that patients with OCD, irrespective of medications, demonstrate significant CSP deficits and excessive ICF compared with healthy subjects, reflecting a disruption in $\mathrm{GABA}_{\mathrm{B}}$ and NMDA receptor-mediated neurotransmission. As described above, such deficits are consistent with proposed mechanisms of OCD pathogenesis (Rosenberg and Keshavan 1998). The observed deficits in $\mathrm{GABA}_{\mathrm{B}}$ receptor-mediated inhibition are consistent with a study implicating the $\mathrm{GABA}_{\mathrm{B}}$ receptor 1 (GABBR1) gene in susceptibility gene to OCD (Zai et al, 2005). Additionally, our findings of increased ICF in OCD are in line with a wellreplicated finding of association between the neuronal glutamate transporter gene SLC1A1 and OCD (Arnold et al, 2006; Dickel et al, 2006; Liang et al, 2008; Stewart et al, 2007). This gene is highly expressed within the cerebral cortex, striatum, and thalamus regions that are clearly implicated in OCD.

Deficits in $\mathrm{GABA}_{B}$ receptor-mediated inhibition as demonstrated by shortened CSP have been shown in other psychiatric disorders such as schizophrenia, bipolar disorder, and major depressive disorder (MDD) (Daskalakis et al, 2002a; Fitzgerald et al, 2002; Levinson et al, 2007; Liu et al, 2009). Therefore, $\mathrm{GABA}_{\mathrm{B}}$ deficits may be a more general marker of psychopathology rather than specifically related to OCD. However, previous studies in mood disorders and schizophrenia have not demonstrated a concomitant increase in ICF (Daskalakis et al, 2002a; Fitzgerald et al, 2002; Levinson et al, 2007, 2010). That is, although other psychiatric disorders appear to be associated with CSP and SICI deficits (eg, major depressive disorder and schizophrenia) the pattern of neurophysiological deficits demonstrated in OCD (ie, decreased CSP and increased ICF) may be specific to this disorder. The specificity of these findings is further strengthened by the fact that after excluding patients with OCD and comorbid MDD from the analysis, differences between OCD patients and healthy controls on CSP and ICF measures remained significant. Taken together, such findings represent a potential biomarker for OCD but require replication in future studies, which should also evaluate the heritability of this neurophysiological profile of response.

To our knowledge, our study involves the largest sample of unmedicated patients with OCD $(n=23)$. This is highly relevant as it has been shown that pharmacological treatment with some antipsychotics (eg, clozapine and haloperidol), benzodiazepines (eg, lorazepam, diazepam), antidepressants (eg, citalopram, paroxetine, sertraline, and mirtazapine), and NMDA antagonists (eg, memantine) can 
lead to changes in CI in healthy subjects and in patients with schizophrenia and depression (Daskalakis et al, 2008a; Minelli et al, 2010; Paulus et al, 2008). For example, it has been shown that clozapine increases CSP (Daskalakis et al, 2008a), haloperidol decreases SICI and increases ICF, diazepam and lorazepam decrease MEP, ICF, and CSP and increase SICI, memantine increases SICI and decreases ICF, citalopram increases MT, CSP, and SICI, and sertraline decreases ICF (Paulus et al, 2008; Robol et al, 2004; Schwenkreis et al, 1999; Ziemann et al, 1996a). However, our finding of no significant differences between medicated and unmedicated patients on CSP and ICF indices suggests that these neurophysiological abnormalities are trait related and unaffected by pharmacological treatment. This is further supported by our analyses showing no relationship between symptom severity, based on total Y-BOCS, or obsession/compulsion subscales, suggesting these neurophysiological findings are not state-dependent. Similarly, analysis by symptom subtype was also negative. Although the power of our subtype analysis was limited, the lack of relationship with any one-symptom subgroup is in contradistinction to views that these subtypes may reflect underlying genetic/neurobiological differences.

Dysregulation of cortical activity is presumed to result from aberrantly modulated subcortical input, as shown by studies in disorders that involve basal ganglia pathology, such as Parkinson's disease, TD, focal dystonias, and OCD (Rauch and Savage, 1997). As mentioned, evidence from functional imaging, and the results of stereotactic ablation and deep brain stimulation studies (Greenberg et al, 2010) strongly suggest that OCD involves hyperactivity of circuits including the frontal cortex, striatum, globus pallidus, and thalamus. As the motor cortex is the target of a motor corticobasothalamic circuit previously implicated in OCD (Greenberg et al, 2000), the deficits of cortical inhibition could be seen as a corollary of the interaction between these hyperactive circuits and the neurons in the motor cortex. A recent metaanalysis (Rotge et al, 2009) comparing patients with OCD to healthy subjects reported that OCD patients have a smaller volume in both ACC and OFC, as well as an increase of the thalamic volume, further supporting thalamocortical involvement in the pathophysiology of OCD. It follows that excessively high outputs generated by an enlarged thalamus and transmitted to the cortex via these pathways are not sufficiently inhibited by volumereduced cortical areas such as the ACC and OFC, resulting in cortical hyperactivity and deficient inhibition.

Our findings of increased RMT and decreased SICI in the left hemisphere of OCD patients with comorbid MDD but not in OCD patients without comorbid MDD are in line with previous studies that have demonstrated increased RMT and SICI deficits in patients with MDD (Lefaucheur et al, 2008; Levinson et al, 2010), and suggest a more marked GABAergic deficit in this population. The fact that OCD patients with comorbid MDD also appeared to demonstrate larger CSP deficits and excessive ICF compared with OCD patients without comorbid MDD, albeit not significantly so, further confirms this finding. This is consistent with neuroimaging studies using positron emission tomography that have demonstrated pathophysiological correlates common to unipolar depression, bipolar depression, and OCD patients with comorbid MDD (Baxter et al, 1989). A pattern of reduced metabolic activity in the left hippocampal region common to patients with MDD and patients with concurrent OCD and MDD, but not in OCD patients alone, has also been previously reported (Saxena et al, 2001). When considered together, these studies suggest that a diagnosis of comorbid MDD adds a separate element of pathophysiology independent of OCD itself.

Our results differ from previous studies in some important ways. First, it was previously reported that the RMT, a marker of ion-channel induced excitability in the cortex (Chen et al, 1997; Ziemann et al, 1996b) that is unrelated to GABA (Ziemann et al, 1996b), glutamate (Liepert et al, 1997; Ziemann et al, 1998), or dopamine transmission (Ziemann et al, 1997b), was decreased in patients with OCD (Greenberg et al, 2000). These differences were not found in our study. Such findings could be accounted for by differences in symptoms severity in our sample compared with previous samples owing to the large number of unmedicated patients. That is, our sample of patients with OCD had greater symptom severity (ie, moderate to severe illness, as reflected in a mean Y-BOCS of 24.34) compared with the sample by Greenberg et al (2000), which reported subclinical mean severity of 14.6 on the Y-BOCS. We also included a higher percentage of unmedicated patients (67.6\%) compared with $43.75 \%$ in the aforementioned study. Greenberg et al (2000) did not find CSP differences between patients with OCD and healthy controls. This may be simply related to the lower stimulation intensities used to generate the CSP (ie, 110 and $120 \%$ of MT) (Greenberg et al, 2000). By contrast, our findings are indeed consistent with Ziemann et al (1997a), who reported shorter CSP and no differences in RMT between patients with TD and comorbid OCD, and healthy subjects. Given these inconsistencies, however, independent replication is warranted.

Our study has some limitations. First, the measurement of CI was restricted to the motor cortex. As mentioned, several brain areas have been implicated in the pathophysiology of OCD including the OFC, DLPFC, basal ganglia structures, ACC, and SMA. Thus, the motor cortex may not be an ideal brain structure to identify abnormalities in a disorder that is more closely related to thoughts and behavior. Recent studies combining TMS with EEG have been shown to effectively measure CI in non-motor cortical regions (Daskalakis et al, 2008b) and should be used to extend our findings to brain regions more closely related to the pathophysiology of this disorder. Second, we evaluated patients with OCD and healthy subjects at a single time point. One of our future directions is to evaluate CI before and after treatment for OCD (eg, serotonin reuptake inhibitors and cognitive behavioral therapy) to determine whether or not potentiation of CI and/or normalization of cortical inhibition or facilitation are related to therapeutic response in these patients.

In summary, our neurophysiological findings suggest that OCD is associated with a dysregulation of both $\mathrm{GABA}_{B}$ receptor-mediated inhibition and of NMDA receptormediated facilitation. Future studies are needed to replicate such findings, evaluate their potential as biomarkers by exploring the heritability of such an intermediate phenotype, and also evaluate such abnormalities in different cortical regions that are also postulated to be more closely 
associated with the pathophysiology of this disorder (ie, DLPFC and OFC).

\section{ACKNOWLEDGEMENTS}

This work was funded, in part, by the Ontario Mental Health Foundation (ZJD), the Canadian Institutes of Health Research Clinician Scientist Award (ZJD), Ontario Mental Health Foundation (MAR) and the International OCD Foundation (MAR), and Constance and Stephen Lieber through a National Alliance for Research on Schizophrenia and Depression (NARSAD) Young Investigator award (ZJD), NHMRC Practitioner Fellowship (PBF), and a NARSAD Independent Investigator Award (ZJD). We acknowledge the assistance of all persons and volunteers whose participation was very important in the completion of the study.

\section{DISCLOSURE}

ZJD has received external funding through Neuronetics and through Aspect Medical, and a travel allowance through Pfizer. PBF has received equipment for research from MagVenture A/S, Brainsway and Medtronic. The author MAR has also received grant funding from Eli Lilly, Canada. ZJD has received speaker funding through Sepracor. All other authors declare no conflict of interest.

\section{REFERENCES}

Arnold PD, Rosenberg DR, Mundo E, Tharmalingam S, Kennedy JL, Richter MA (2004). Association of a glutamate (NMDA) subunit receptor gene (GRIN2B) with obsessive-compulsive disorder: a preliminary study. Psychopharmacology (Berl) 174: 530-538.

Arnold PD, Sicard T, Burroughs E, Richter MA, Kennedy JL (2006). Glutamate transporter gene SLC1A1 associated with obsessivecompulsive disorder. Arch Gen Psychiatry 63: 769-776.

Baxter Jr LR, Schwartz JM, Phelps ME, Mazziotta JC, Guze BH, Selin CE et al (1989). Reduction of prefrontal cortex glucose metabolism common to three types of depression. Arch Gen Psychiatry 46: 243-250.

Beck AT, Beamesderfer A (1974). Assessment of depression: the depression inventory. Mod Probl Pharmacopsychiatry 7: 151-169.

Cantello R, Gianelli M, Civardi C, Mutani R (1992). Magnetic brain stimulation: the silent period after the motor evoked potential. Neurology 42: 1951-1959.

Chamberlain SR, Blackwell AD, Fineberg NA, Robbins TW, Sahakian BJ (2005). The neuropsychology of obsessive compulsive disorder: the importance of failures in cognitive and behavioural inhibition as candidate endophenotypic markers. Neurosci Biobehav Rev 29: 399-419.

Chen R, Samii A, Canos M, Wassermann EM, Hallett M (1997). Effects of phenytoin on cortical excitability in humans. Neurology 49: 881-883.

Daskalakis ZJ, Christensen BK, Chen R, Fitzgerald PB, Zipursky RB, Kapur S (2002a). Evidence for impaired cortical inhibition in schizophrenia using transcranial magnetic stimulation. Arch Gen Psychiatry 59: 347-354.

Daskalakis ZJ, Christensen BK, Fitzgerald PB, Chen R (2002b). Transcranial magnetic stimulation: a new investigational and treatment tool in psychiatry. J Neuropsychiatry Clin Neurosci 14: 406-415.
Daskalakis ZJ, Christensen BK, Fitzgerald PB, Moller B, Fountain SI, Chen R (2008a). Increased cortical inhibition in persons with schizophrenia treated with clozapine. J Psychopharmacol 22: 203-209.

Daskalakis ZJ, Farzan F, Barr MS, Rusjan PM, Favalli G, Levinson $\mathrm{AJ}$ et al (2008b). Evaluating the relationship between long interval cortical inhibition, working memory and gamma band activity in the dorsolateral prefrontal cortex. Clin EEG Neurosci 39: 150-155.

Daskalakis ZJ, Molnar GF, Christensen BK, Sailer A, Fitzgerald PB, Chen R (2003). An automated method to determine the transcranial magnetic stimulation-induced contralateral silent period. Clin Neurophysiol 114: 938-944.

Davies CH, Davies SN, Collingridge GL (1990). Paired-pulse depression of monosynaptic GABA-mediated inhibitory postsynaptic responses in rat hippocampus. J Physiol 424: 513-531.

Dickel DE, Veenstra-VanderWeele J, Cox NJ, Wu X, Fischer DJ, Van Etten-Lee $M$ et al (2006). Association testing of the positional and functional candidate gene SLC1A1/EAAC1 in early-onset obsessive-compulsive disorder. Arch Gen Psychiatry 63: 778-785.

Fitzgerald PB, Brown TL, Daskalakis ZJ, Kulkarni J (2002). A transcranial magnetic stimulation study of inhibitory deficits in the motor cortex in patients with schizophrenia. Psychiatry Res 114: 11-22.

Fuhr P, Agostino R, Hallett M (1991). Spinal motor neuron excitability during the silent period after cortical stimulation. Electroencephalogr Clin Neurophysiol 81: 257-262.

Goodman WK, Price LH, Rasmussen SA, Mazure C, Delgado P, Heninger GR et al (1989a). The Yale-Brown Obsessive Compulsive Scale. II. Validity. Arch Gen Psychiatry 46: 1012-1016.

Goodman WK, Price LH, Rasmussen SA, Mazure C, Fleischmann RL, Hill CL et al (1989b). The Yale-Brown Obsessive Compulsive Scale. I. Development, use, and reliability. Arch Gen Psychiatry 46: 1006-1011.

Graybiel AM, Rauch SL (2000). Toward a neurobiology of obsessive-compulsive disorder. Neuron 28: 343-347.

Greenberg BD, Gabriels LA, Malone Jr DA, Rezai AR, Friehs GM, Okun MS et al (2010). Deep brain stimulation of the ventral internal capsule/ventral striatum for obsessive-compulsive disorder: worldwide experience. Mol Psychiatry 15: 64-79.

Greenberg BD, Ziemann U, Cora-Locatelli G, Harmon A, Murphy DL, Keel JC et al (2000). Altered cortical excitability in obsessivecompulsive disorder. Neurology 54: 142-147.

Greenberg BD, Ziemann U, Harmon A, Murphy DL, Wassermann EM (1998). Decreased neuronal inhibition in cerebral cortex in obsessive-compulsive disorder on transcranial magnetic stimulation. Lancet 352: 881-882.

Karno M, Golding JM, Sorenson SB, Burnam MA (1988). The epidemiology of obsessive-compulsive disorder in five US communities. Arch Gen Psychiatry 45: 1094-1099.

Koran LM, Thienemann ML, Davenport R (1996). Quality of life for patients with obsessive-compulsive disorder. Am J Psychiatry 153: 783-788.

Kujirai T, Caramia MD, Rothwell JC, Day BL, Thompson PD, Ferbert A et al (1993). Corticocortical inhibition in human motor cortex. J Physiol 471: 501-519.

Lefaucheur JP, Lucas B, Andraud F, Hogrel JY, Bellivier F, Del Cul A et al (2008). Inter-hemispheric asymmetry of motor corticospinal excitability in major depression studied by transcranial magnetic stimulation. J Psychiatr Res 42: 389-398.

Levinson AJ, Fitzgerald PB, Favalli G, Blumberger DM, Daigle M, Daskalakis ZJ (2010). Evidence of cortical inhibitory deficits in major depressive disorder. Biol Psychiatry 67: 458-464.

Levinson AJ, Young LT, Fitzgerald PB, Daskalakis ZJ (2007). Cortical inhibitory dysfunction in bipolar disorder: a study using transcranial magnetic stimulation. J Clin Psychopharmacol 27: 493-497. 
Liang KY, Wang Y, Shugart YY, Grados M, Fyer AJ, Rauch S et al (2008). Evidence for potential relationship between SLC1A1 and a putative genetic linkage region on chromosome $14 \mathrm{q}$ to obsessive-compulsive disorder with compulsive hoarding. Am J Med Genet B Neuropsychiatr Genet 147B: 1000-1002.

Liepert J, Schwenkreis P, Tegenthoff M, Malin JP (1997). The glutamate antagonist riluzole suppresses intracortical facilitation. J Neural Transm 104: 1207-1214.

Liu SK, Fitzgerald PB, Daigle M, Chen R, Daskalakis ZJ (2009). The relationship between cortical inhibition, antipsychotic treatment, and the symptoms of schizophrenia. Biol Psychiatry 65: 503-509.

Maltby N, Tolin DF, Worhunsky P, O’Keefe TM, Kiehl KA (2005). Dysfunctional action monitoring hyperactivates frontal-striatal circuits in obsessive-compulsive disorder: an event-related fMRI study. Neuroimage 24: 495-503.

Minelli A, Bortolomasi M, Scassellati C, Salvoro B, Avesani M, Manganotti P (2010). Effects of intravenous antidepressant drugs on the excitability of human motor cortex: a study with paired magnetic stimulation on depressed patients. Brain Stimul 3: 15-21.

Morey LC (1991). Personality Assessment Inventory_-Professional Manual. Psychological Assessment Resources: Florida.

Morey LC (1996). An interpretive Guide to the Personality Assessment Inventory (PAI). Psychological Assessment Resources: Florida.

Page LA, Rubia K, Deeley Q, Daly E, Toal F, Mataix-Cols D et al (2009). A functional magnetic resonance imaging study of inhibitory control in obsessive-compulsive disorder. Psychiatry Res 174: 202-209.

Paulus W, Classen J, Cohen LG, Large CH, Di Lazzaro V, Nitsche M et al (2008). State of the art: pharmacologic effects on cortical excitability measures tested by transcranial magnetic stimulation. Brain Stimul 1: 151-163.

Rauch SL, Savage CR (1997). Neuroimaging and neuropsychology of the striatum. Bridging basic science and clinical practice. Psychiatr Clin North Am 20: 741-768.

Richter MA, Summerfeldt LJ, Antony MM, Swinson RP (2003). Obsessive-compulsive spectrum conditions in obsessive-compulsive disorder and other anxiety disorders. Depress Anxiety 18: 118-127.

Robol E, Fiaschi A, Manganotti P (2004). Effects of citalopram on the excitability of the human motor cortex: a paired magnetic stimulation study. J Neurol Sci 221: 41-46.

Roick H, von Giesen HJ, Benecke R (1993). On the origin of the postexcitatory inhibition seen after transcranial magnetic brain stimulation in awake human subjects. Exp Brain Res 94: 489-498.

Rosenberg DR, Keshavan MS (1998). A.E. Bennett Research Award. Toward a neurodevelopmental model of obsessive-compulsive disorder. Biol Psychiatry 43: 623-640.

Rosenberg DR, MacMaster FP, Keshavan MS, Fitzgerald KD, Stewart CM, Moore GJ (2000). Decrease in caudate glutamatergic concentrations in pediatric obsessive-compulsive disorder patients taking paroxetine. J Am Acad Child Adolesc Psychiatry 39: 1096-1103.

Rossi S, Bartalini S, Ulivelli M, Mantovani A, Di Muro A, Goracci A et al (2005). Hypofunctioning of sensory gating mechanisms in patients with obsessive-compulsive disorder. Biol Psychiatry 57: $16-20$.

Rotge JY, Guehl D, Dilharreguy B, Tignol J, Bioulac B, Allard M et al (2009). Meta-analysis of brain volume changes in obsessivecompulsive disorder. Biol Psychiatry 65: 75-83.

Ruscio AM, Stein DJ, Chiu WT, Kessler RC (2010). The epidemiology of obsessive-compulsive disorder in the National Comorbidity Survey Replication. Mol Psychiatry 15: 53-63.

Saxena S, Brody AL, Ho ML, Alborzian S, Ho MK, Maidment KM et al (2001). Cerebral metabolism in major depression and obsessive-compulsive disorder occurring separately and concurrently. Biol Psychiatry 50: 159-170.
Saxena S, Brody AL, Schwartz JM, Baxter LR (1998). Neuroimaging and frontal-subcortical circuitry in obsessive-compulsive disorder. Br J Psychiatry Suppl 35: 26-37.

Schwenkreis P, Witscher K, Janssen F, Addo A, Dertwinkel R, Zenz $\mathrm{M}$ et al (1999). Influence of the N-methyl-D-aspartate antagonist memantine on human motor cortex excitability. Neurosci Lett 270: $137-140$

Siebner HR, Dressnandt J, Auer C, Conrad B (1998). Continuous intrathecal baclofen infusions induced a marked increase of the transcranially evoked silent period in a patient with generalized dystonia. Muscle Nerve 21: 1209-1212.

Stewart SE, Rosario MC, Brown TA, Carter AS, Leckman JF, Sukhodolsky D et al (2007). Principal components analysis of obsessive-compulsive disorder symptoms in children and adolescents. Biol Psychiatry 61: 285-291.

Summerfeldt LJ, Richter MA, Antony MM, Swinson RP (1999). Symptom structure in obsessive-compulsive disorder: a confirmatory factor-analytic study. Behav Res Ther 37: 297-311.

Tergau F, Wanschura V, Canelo M, Wischer S, Wassermann EM, Ziemann U et al (1999). Complete suppression of voluntary motor drive during the silent period after transcranial magnetic stimulation. Exp Brain Res 124: 447-454.

van den Heuvel OA, Veltman DJ, Groenewegen HJ, Cath DC, van Balkom AJ, van Hartskamp J et al (2005). Frontal-striatal dysfunction during planning in obsessive-compulsive disorder. Arch Gen Psychiatry 62: 301-309.

Weissman MM, Bland RC, Canino GJ, Greenwald S, Hwu HG, Lee CK et al (1994). The cross national epidemiology of obsessive compulsive disorder. The Cross National Collaborative Group. J Clin Psychiatry 55(Suppl): 5-10.

Werhahn KJ, Kunesch E, Noachtar S, Benecke R, Classen J (1999). Differential effects on motorcortical inhibition induced by blockade of GABA uptake in humans. J Physiol 517(Part 2): 591-597.

Whiteside SP, Port JD, Abramowitz JS (2004). A meta-analysis of functional neuroimaging in obsessive-compulsive disorder. Psychiatry Res 132: 69-79.

Woolley J, Heyman I, Brammer M, Frampton I, McGuire PK, Rubia $\mathrm{K}$ (2008). Brain activation in paediatric obsessive compulsive disorder during tasks of inhibitory control. Br J Psychiatry 192: 25-31.

Yucel M, Harrison BJ, Wood SJ, Fornito A, Wellard RM, Pujol J et al (2007). Functional and biochemical alterations of the medial frontal cortex in obsessive-compulsive disorder. Arch Gen Psychiatry 64: 946-955.

Zai G, Arnold P, Burroughs E, Barr CL, Richter MA, Kennedy JL (2005). Evidence for the gamma-amino-butyric acid type B receptor 1 (GABBR1) gene as a susceptibility factor in obsessivecompulsive disorder. Am J Med Genet B Neuropsychiatr Genet 134B: 25-29.

Ziemann U, Chen R, Cohen LG, Hallett M (1998). Dextromethorphan decreases the excitability of the human motor cortex. Neurology 51: 1320-1324.

Ziemann U, Lonnecker S, Steinhoff BJ, Paulus W (1996a). The effect of lorazepam on the motor cortical excitability in man. Exp Brain Res 109: 127-135.

Ziemann U, Lonnecker S, Steinhoff BJ, Paulus W (1996b). Effects of antiepileptic drugs on motor cortex excitability in humans: a transcranial magnetic stimulation study. Ann Neurol 40: 367-378.

Ziemann U, Paulus W, Rothenberger A (1997a). Decreased motor inhibition in Tourette's disorder: evidence from transcranial magnetic stimulation. Am J Psychiatry 154: 1277-1284.

Ziemann U, Tergau F, Bruns D, Baudewig J, Paulus W (1997b). Changes in human motor cortex excitability induced by dopaminergic and anti-dopaminergic drugs. Electroencephalogr Clin Neurophysiol 105: 430-437. 